\title{
Global transcriptional activity dynamics reveal functional enhancer RNAs
}

\author{
Yoon Jung Kim, ${ }^{1,2}$ Peng Xie, ${ }^{1,2}$ Lian Cao, ${ }^{1}$ Michael Q. Zhang, ${ }^{1}$ and Tae Hoon Kim ${ }^{1}$ \\ ${ }^{1}$ Department of Biological Sciences and Center for Systems Biology, University of Texas at Dallas, Richardson, Texas 75080, USA
}

\begin{abstract}
Active enhancers of the human genome generate long noncoding transcripts known as enhancer RNAs (eRNAs). How dynamic transcriptional changes of eRNAs are physically and functionally linked with target gene transcription remains unclear. To investigate the dynamic functional relationships among eRNAs and target promoters, we obtained a dense time series of GRO-seq and ChIP-seq data to generate a time-resolved enhancer activity map of a cell undergoing an innate antiviral immune response. Dynamic changes in eRNA and pre-mRNA transcription activities suggest distinct regulatory roles of enhancers. Using a criterion based on proximity and transcriptional inducibility, we identified 123 highly confident pairs of virus-inducible enhancers and their target genes. These enhancers interact with their target promoters transiently and concurrently at the peak of gene activation. Accordingly, their physical disassociation from the promoters is likely involved in post-induction repression. Functional assessments further establish that these eRNAs are necessary for full induction of the target genes and that a complement of inducible eRNAs functions together to achieve full activation. Lastly, we demonstrate the potential for eRNA-targeted transcriptional reprogramming through targeted reduction of eRNAs for a clinically relevant gene, TNFSF10, resulting in a selective control of interferon-induced apoptosis.
\end{abstract}

[Supplemental material is available for this article.]

Enhancers are key cis-regulatory elements that play an essential role in genome expression to determine cell fates and functions. There are millions of enhancers in the human genome, and these enhancers function to shape cell identity by directing distinct genome expression programs. In practice, these enhancers can be systematically identified by the presence of histone modification of H3K4me1 (Heintzman et al. 2007, 2009) and H3K27ac (Rada-Iglesias et al. 2011), the association of transcription factors and coactivators (Heinz et al. 2015), and/or DNase I hypersensitivity (The ENCODE Project Consortium 2007; Thurman et al. 2012). Functional hierarchies among these enhancers have been described (Ernst and Kellis 2010). Recently, enhancers were found to be transcriptionally active and generate noncoding RNAs known as enhancer RNAs (eRNAs) as relatively unstable transcripts (Kim et al. 2010; Wang et al. 2011). Several studies have demonstrated eRNA-producing enhancers are more potent and associated with higher expression of nearby genes than enhancers without eRNAs (Wang et al. 2011; Heinz et al. 2015; Romanoski et al. 2015) and transcriptional activity at enhancers precedes target gene expression (Arner et al. 2015). Thus, eRNA-producing enhancers are likely active and functional enhancers that define the identity and function of a given cell. Moreover, targeting enhancer activity for therapeutic development has been recently proposed and pursued by several groups and companies (Bradner et al. 2017). By targeting particular enhancers, disease-specific modulation of gene expression would be possible without affecting the normal expression in other tissues and organs. However, for the over two million enhancers that have been annotated (Roadmap

\footnotetext{
${ }^{2}$ These authors contributed equally to this work. Corresponding authors: michael.zhang@utdallas.edu, genome@utdallas.edu

Article published online before print. Article, supplemental material, and publication date are at http://www.genome.org/cgi/doi/10.1101/gr.233486.117. Freely available online through the Genome Research Open Access option.
}

Epigenomics Consortium et al. 2015), currently only tens of thousands of eRNAs have been detected in the human genome through isolated studies (Li et al. 2016). A systematic detection and annotation of eRNAs is necessary to enable functional characterization of eRNA gene regulation, which is a fundamental step toward therapeutic development.

In-depth studies of eRNAs in regulation of key biological processes require accurate prediction of target genes. Existing methods are mostly based on eRNA and mRNA levels in steady-state cells, which may not provide enough information for functional associations. Active enhancers may have multiple nearby genes and vice versa, but functionally associated pairs will be triggered to be transcriptionally active in a synchronized fashion. Thus, eRNA/pre-mRNA dynamics, induced by a stimulus, may represent a highly informative feature for more reliable enhancer target predictions (Arner et al. 2015). For example, in our previous study (Banerjee et al. 2014), we took advantage of the dynamic physical chromatin interactions to identify a functional enhancer responsible for the IFNB1 gene, a critical component of innate and adaptive immunity.

In order to systematically investigate the functionality of eRNAs in the human genome, we have employed a battery of comprehensive, unbiased functional genomic experiments across multiple time points to annotate and investigate the dynamics of enhancer and target gene activation. We also design a novel computational strategy for determining functional eRNAs that are virus-inducible and mediate innate anti-viral response. Combined with functional assessment using RNAi and time course chromosome conformation capture (3C), we examine functional relevance of these virus-inducible eRNAs, their regulatory trajectories, and modes of action.

(C) 2018 Kim et al. This article, published in Genome Research, is available under a Creative Commons License (Attribution 4.0 International), as described at http://creativecommons.org/licenses/by/4.0/. 


\section{Results}

\section{A time-resolved enhancer activity map}

In order to obtain the informative features of eRNA/mRNA dynamics, we performed a large time series GRO-seq analysis of B-lymphoblasts (GM12878) during innate anti-viral immune response. We used Sendai Virus (SeV) to activate the immune response signalcascade gene induction system as a model to study the anti-viral program. We first combined all GRO-seq data obtained from 12 time points from 0 to $72 \mathrm{~h}$ post-infection to determine a compendium of eRNA-producing enhancers responding to virus, then used HOMER (Heinz et al. 2010) to identify the eRNA transcripts (see Methods). Of 32,832 total intergenic transcripts, 11,025 transcripts overlapped with H3K4me1 or H3K27ac histone modification peaks, representative enhancer marks (Fig. 1A). We annotated transcription start/termination sites (TSSs/TTSs) for the 11,025 eRNAs (Fig. 1B). The average predicted length of eRNAs from our annotation efforts was $1746 \mathrm{bp}$ (Supplemental Fig. S1A). Other enhancer marks including EP300 and DNase hypersensitivity signals were highly enriched at the TSSs of eRNAs (Fig. 1C; Lai and Pugh 2017). Additionally, the patterns of H3K4me1 and H3K27ac ChIP-seq, DNase hypersensitivity and MNase-seq indicated an open chromatin region at the eRNA TSSs. Notably, a majority (64\%) of the eRNAs were below detection levels prior to virus infection, thereby indicating a dramatic induction of eRNA synthesis upon virus infection (Fig. 1A). We have compared the resulting eRNA annotation to the previous large-scale analysis of 43,012 eRNAs obtained from 69 human cell types by the FANTOM consortium (Andersson et al. 2014). Only $28 \%$ of our eRNA annotations overlapped with that of the FANTOM5 human enhancer atlas (Andersson et al. 2014), underscoring condition-specific differences. In addition, we found 18,999 intergenic transcripts, lacking initial eRNA production and enhancer marks, being transcribed after infection. These transcripts showed similar lengths as eRNAs defined above ( $P$-value $0.14, t$-test). A previous study showed that enhancers initially lacking known enhancer marks, like the 18,999
A experimental design

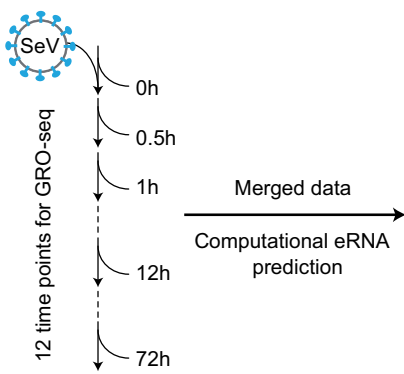

C ChIP-seq signals near eRNA TSSs

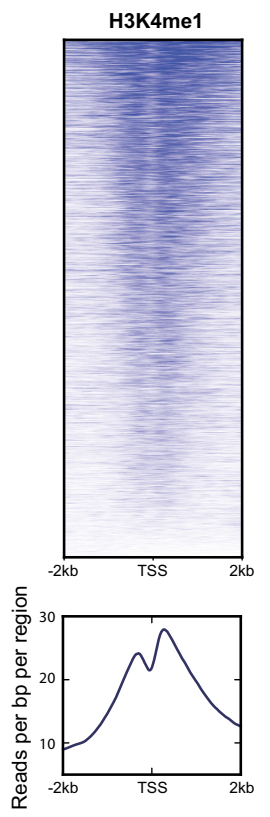

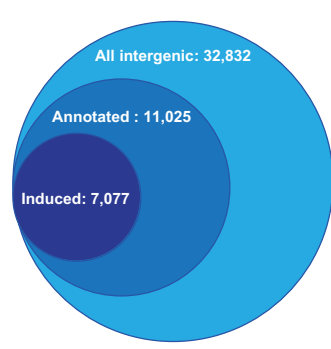
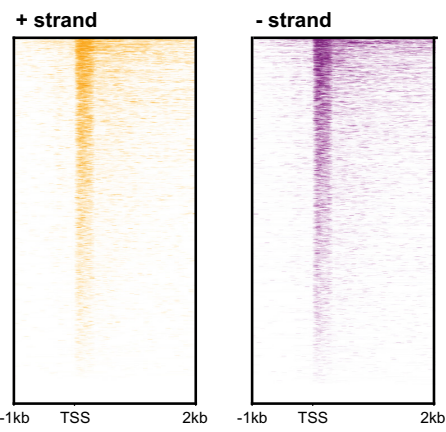

DNase HS
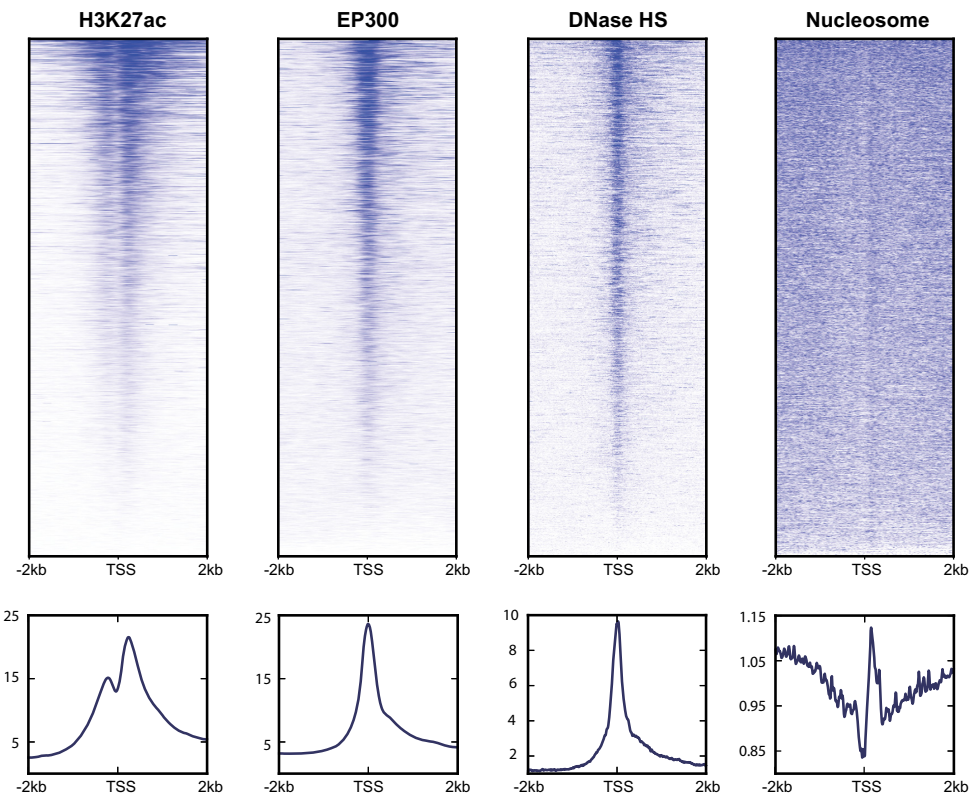
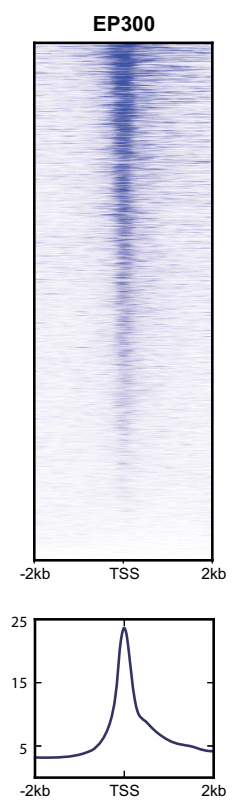
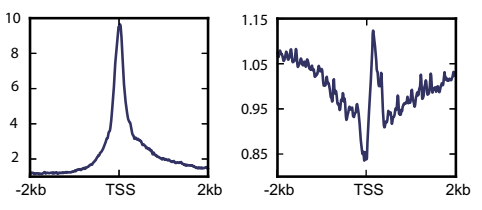

Figure 1. Genome-wide eRNA identification. (A) Venn diagram shows the number of all the intergenic transcribed regions (outer circle, light blue), high confidence enhancer regions (middle circle, blue), and inducible enhancer regions (inner circle, dark blue). (B) Heat map summarizes GRO-seq data in eRNA-TSS flanking regions (from $1 \mathrm{~kb}$ upstream to $2 \mathrm{~kb}$ downstream). eRNAs from + (yellow) and - (purple) strands are shown separately. Predicted eRNA-expressing enhancer regions are centered at the TSS. (C) Heat map (upper panel) and metagene profiles (lower panel) are plotted for epigenetic signals including H3K4me1, H3K27ac, and EP300 ChIP-seq, DNase-seq, and MNase-seq data.

\section{Genome Research}

www.genome.org 
enhancers that we found here, could acquire enhancer-associated epigenetic modifications upon stimuli (Kaikkonen et al. 2013).

\section{Rapid and dynamic transcriptional response of genes and enhancers}

We quantified expression levels of the RefSeq genes and performed differential expression (DE) analysis. Based on the expression dynamics of DE genes (Fig. 2A), the time course can be divided into three stages: 0-2 h, limited changes; $4-24 \mathrm{~h}$, significant changes with more induced genes (early-up) than repressed; 48-72 h, large changes comprised of both up- (late-up) and down- (late-down) regulated genes. To understand these expression dynamics more meaningfully, we performed Gene Ontology (GO) analysis at each time point (Supplemental Fig. S1B). DE gene-enriched functions were highly consistent between time points within each of the three stages. For example, the most frequently enriched GO terms of early-up, late-up, and late-down groups were "responses to virus," "apoptosis," and "cell cycle," respectively. We also performed DE analysis with the annotated eRNAs. Their expression dynamics could also be divided into three stages, exactly matching those of DE genes (Fig. 2B). Representative examples of inducible genes and eRNAs are shown in Supplemental Figure S1C,D. Furthermore, nearest genes of the inducible eRNAs (described in the section describing enhancer-promoter pairs) were functionally enriched in immune system processes (Fig. 2C).

To visualize and verify the dynamics of eRNA and gene expression patterns, we performed principal component analysis (PCA),

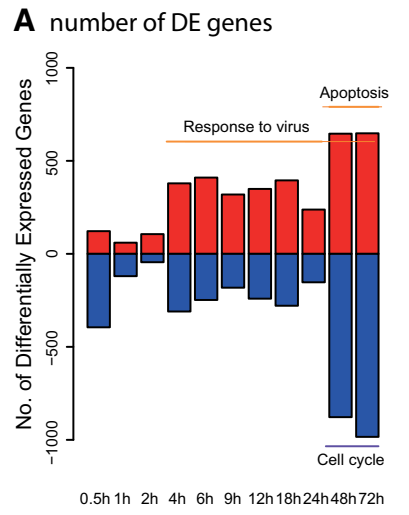

B number of DE eRNAs

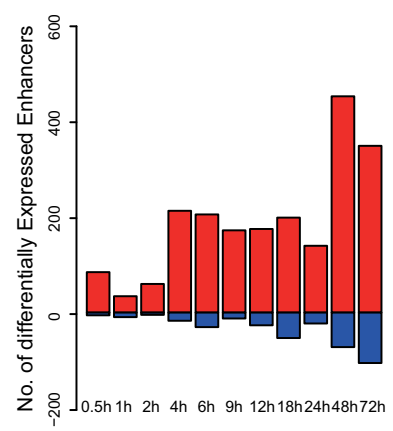

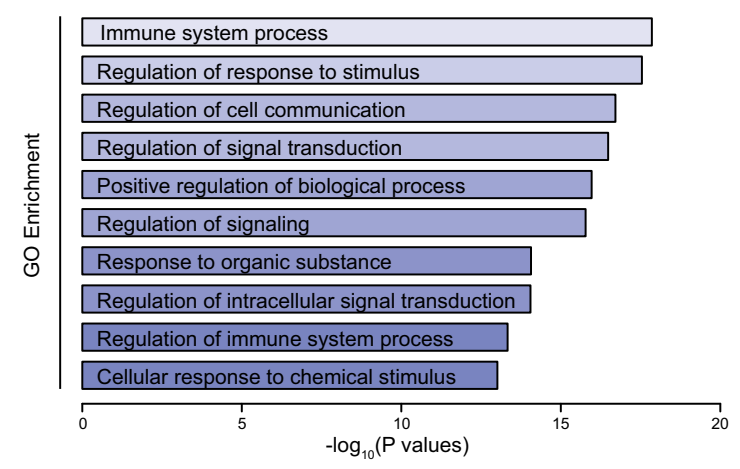

D PCA at mRNA gene level

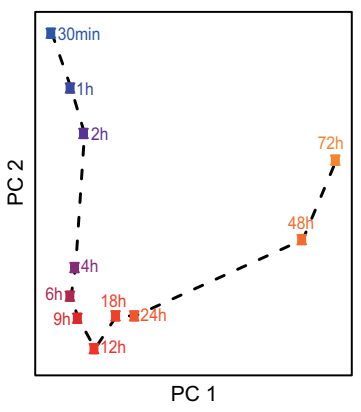

C GO analysis of genes nearby DE eRNAs

Figure 2. Analysis of differentially expressed genes. (A) Number of up- (red) and down- (blue) regulated genes in time course after virus infection. (B) Number of up- (red) and down- (blue) regulated enhancers through time course. $(C)$ Bar plot of $G O$ terms enriched in the nearest genes linked to the inducible enhancers. $(D, E)$ First two principal components of PCA analysis based on mRNA $(D)$ and eRNA $(E)$ expression level. The plots are color-coded by time points: blue (early) and orange (late). which showed a trajectory of cellular states (Fig. 2D,E). The first two principal components (PCs) clearly separated samples from each time points. Principal component 2 (PC2) values showed an interesting trajectory, which moved away from the baseline in early time and returned after $18 \mathrm{~h}$, matching the expression dynamics of immune related genes (GO term "defense response to virus," $P$-value $\left.=2.5 \times 10^{-12}\right)$. Similar analysis was performed for genes correlated with PC1, showing enrichment of GO terms "translation," "apoptosis," and "RNA decay." Likewise, the first two PCs of eRNAs showed similar dynamics as those of gene expression, indicating connected regulatory processes between eRNAs and gene expression. In addition, t-distributed stochastic neighbor embedding (t-SNE) (Jamieson et al. 2010) results showed almost identical patterns (Supplemental Fig. S1E,F).

\section{Cytokine IFNB1 as a representative transient transcript}

As a representative virus-inducible case, we investigated the IFNB1 gene and its enhancer $L 2$, which we previously identified as a novel virus-inducible long-range enhancer regulating IFNB1 transcription in IMR-90 lung fibroblasts (Banerjee et al. 2014). An independent study (Decque et al. 2016) has also demonstrated that the $L 2$ is a major enhancer regulating IFNB1 expression in bone marrowderived dendritic cells and macrophages. Our GRO-seq data in GM12878 cells indicate strong transcription at IFNB1 and the $L 2$ element in early time points just after $\mathrm{SeV}$ infection (Supplemental Fig. S2). L2 eRNA was transcribed first at $1 \mathrm{~h}$, and then IFNB1 transcript emerged around $1 \mathrm{~h}$ after $L 2$, implying that eRNA generation precedes target gene transcription. $L 2$ transcription continues to be detected even at $72 \mathrm{~h}$ post-infection when IFNB1 has become repressed by post-induction repression mechanisms (Ren et al. 1999), implicating a potentially novel enhancer inactivation and decommissioning mechanism. We also investigated other well-known transcription factors of IRF and NFKB families which are also upregulated at these earliest time points (Supplemental Fig. S2B).

\section{Construction of an enhancer-target gene map for viral response}

Accurate cell-specific and genome-wide enhancer target identification is a challenging task. Despite several improvements in the past few years (Jin et al. 2013; Whalen et al. 2016; Cao et al. 2017), the accuracy is still far from satisfactory for in-depth case studies of individual genes or enhancers. Using metagene analysis, our results, as well as several other studies (Hah et al. 2013; Kaikkonen et al. 2013), have shown the coordinated transcriptional dynamics of enhancers and neighbor genes should be highly enriched with functional targets. Can we take advantage of the paired expression profiles to further refine target prediction for individual enhancers? To this end, we carefully examined the expression profiles of eRNA/gene pairs 
that were significantly activated by $\mathrm{SeV}$ infection. In addition to the expected, correlated pattern of concordant on/off behaviors between enhancers and genes, we also observed a discordant expression pattern showing persistent eRNA transcription after target gene repression (Fig. 3A). This discordant pattern was exhibited by the previously validated L2-IFNB1 EP (enhancer-promoter) pair. Thus, the co-inducibility of eRNAs and target genes is a potentially important feature for inferring functional enhancer targets, regardless of regulatory divergence of the concordant and discordant sets of eRNA/gene pairs. To identify inducible enhancers and genes, we constructed two indices: the continuity index (CI) and the amplitude index (AI) (Fig. 3B; see Methods). The CI is used to filter out random fluctuations in the expression levels, especially for eRNAs which are lowly expressed and more subject to technical variability. The AI is designed to represent the maximum induced levels, which is stable with respect to the specific expression patterns but can be highly variable for each EP pair. In these indices, 299 genes and 787 enhancers were identified as inducible. Consistent with the induced transcriptional activity, the H3K27ac levels of these 787 enhancers were also induced by $\mathrm{SeV}$ infection (Supplemental Fig. S1G).

Genomic proximity is also an important factor for identifying enhancer targets (Sanyal et al. 2012). We found that inducible genes were highly enriched within $200 \mathrm{~kb}$ of the inducible enhanc- ers (Fig. 3C) and vice versa (Supplemental Fig. S3A,E). We assigned the inducible enhancers with the nearest inducible genes within $200 \mathrm{~kb}$ and obtained 123 highly confident enhancer-promoter (EP) pairs (Supplemental Table S1). Extending the proximity window farther enabled us to define more enhancer-promoter pairs, but this increased sensitivity of identifying more EP pairs also resulted in significant increases in the false positive rate for our inducible EP prediction. For example, the percentage of inducible genes decreased from $\sim 50 \%$ to $\sim 30 \%$ if the distance threshold was increased by another $100 \mathrm{~kb}$. In addition, our current analysis focused only on the mRNA encoding target genes and excluded possible target genes encoding noncoding RNAs due to the limited functional information regarding these genes. This highly prioritized inducible eRNA and target gene set included not only the previously validated L2-IFNB1 pair but also other critical genes involved in immune function, such as the CD38, IRF8, TNFSF10, and TLR7 genes, whose distal regulatory elements were largely unknown.

\section{Inducible enhancers have conserved sequences}

Since enhancers activate their target genes by recruiting transcriptional factors (TFs), we hypothesized that these inducible enhancers might have distinct TF binding motifs supporting
A discordant and concordant expression patterns between enhancers and genes
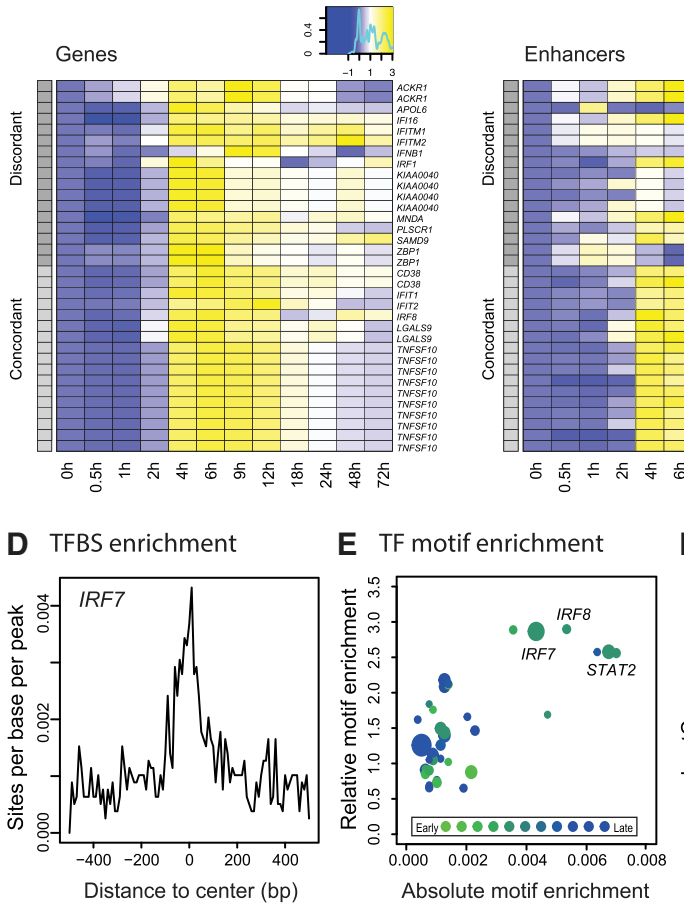

E TF motif enrichment

D TFBS enrichment

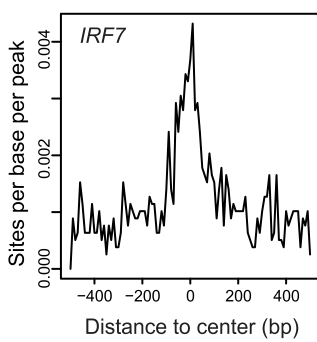

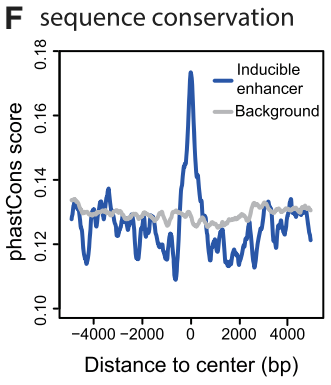

B inducibility criteria, $\mathrm{Al}$ and $\mathrm{Cl}$

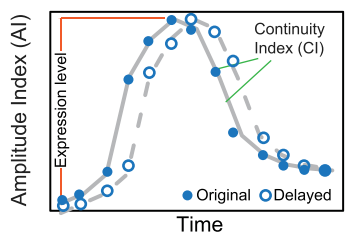

C proportion of inducible genes

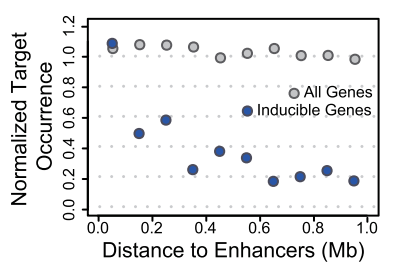

G coexistence of EP pairs

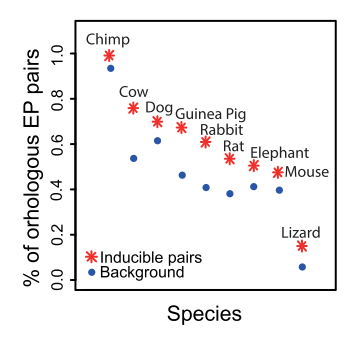

Figure 3. Prediction of virus-inducible enhancer-promoter (EP) pairs and validation of their interactions. (A) Heat map of discordant and concordant expression pairs of target genes (left panel) and their enhancers (right panel). Rows are matched. Expression levels were normalized as log ${ }_{2}$ fold changes relative to $0 \mathrm{~h}$. Gray scales represent discordant (dark gray) and concordant (light gray) groups. (B) Diagram describes the identification of inducible enhancers and genes with two indices: the continuity index $(\mathrm{Cl})$ and the amplitude index (Al). (C) Number of inducible genes as a function of EP distance is analyzed. Inducible genes were counted within each 100-kb bin of inducible enhancers (blue points). As a control, the number of all genes in each bin was calculated (gray points). Each group was normalized by the maximum count for the sake of comparison. (D) Enrichment of TF IRF7 motif in the 1-kb TSS-flanking region of inducible enhancers is shown. ( $E$ ) Motif enrichment of inducible enhancers. $x$-axis (absolute enrichment) is the maximum sites per base per peak (SBP). $y$-axis (relative enrichment) is the SBP ratio between the center ( -100 to $100 \mathrm{bp}$ ) and rest ( -500 to -100 bp and 100 to $500 \mathrm{bp}$ ) of the flanking regions. Point sizes indicate the GRO-seq RPKM fold changes of TFs. Colors indicate the first time point when the TF reaches half induction. $(F)$ Average phastCons conservation scores of primates across inducible enhancer regions are shown, relative to randomly selected background. $(G)$ Percentage of inducible human EP pairs that co-exist in other species is shown.

\section{Genome Research}

www.genome.org 
virus-inducible gene regulation. We analyzed human TF motif occurrences within the inducible enhancers and found a strong enrichment of binding sites for IRF- and STAT-family proteins, which are known interferon-responsive factors (Fig. 3D,E). In addition, IRF7 and STAT2 were up-regulated by more than twofold post-SeV treatment (Fig. 3E). Most TFs with high motif enrichment reached $50 \%$ of their maximum expression levels no later than $6 \mathrm{~h}$ after virus infection (Fig. 3E), thus supporting our hypothesis of enhancer induction through TF activation.

These inducible enhancers showed a significantly higher evolutionary sequence conservation level than carefully selected background regions (Fig. 3F; Supplemental Fig. S3B,C), especially near the TSSs of eRNAs. Synteny of enhancer and promoters across 11 species spanning the vertebrate phylogenetic tree was also examined (see Methods). We found that the induced EP pairs had $\sim 10 \%$ higher chance than the random background to be immobilized on the same chromosome across the 11 vertebrate genomes (Fig. 3G). Moreover, the induced pairs showed a higher probability to remain in close proximity to each other $(<500 \mathrm{~kb})$ (Supplemental Fig. S3D).

\section{Dynamic physical EP association correlated with target gene expression patterns}

Physical interaction between an enhancer and its target promoter has been accepted as a general mechanism of gene activation. It is thought that many inducible genes are regulated through pre-existing interactions with enhancers (Jin et al. 2013); however, the fate of these interactions after induction when the gene is turned off has not been adequately addressed. We examined the dynamic physical interaction of 18 inducible EP pairs using a time course chromosome conformation capture assay. We also sampled 18 active enhancers and genes within $200 \mathrm{~kb}$ that did not pass the inducibility criterion as a control set (Supplemental Tables S2, S3). Most inducible EP pairs showed the highest interaction between enhancer and promoter at $12 \mathrm{~h}$ (Fig. 4A). This transient physical interaction correlated with the corresponding target gene expression profiles (Fig. 4C). In contrast, the control pairs showed highly variable interaction patterns during the time course and a lower inducibility of physical interaction (Fig. 4A,B). The inducible EP pairs showed a significantly higher inducible interaction frequency (Kolmogorov-Smirnov test, $P$-value $=0.0286)($ Fig. $4 \mathrm{~B})$. A notable observation from this analysis is that, in most cases, a decrease in physical interaction after $12 \mathrm{~h}$ post-infection coincided with a concomitant decrease in target gene transcription. Thus, this transient physical EP interaction may determine the maximal promoter activity. In addition, some eRNAs can continue to be transcribed beyond $12 \mathrm{~h}$ post-infection, as in the case for the IFNB1 and $L 2$ and many other EP pairs. Therefore, physical dissociation of an enhancer from its target promoter might be a critical mechanism of post-induction repression of these target genes, irrespective of the status of eRNA synthesis at the enhancers.

\section{Functional relevance of eRNA expression in target gene activation}

Although many eRNAs have been shown to be important for target promoter regulation by a number of studies (Li et al. 2013; Melo et al. 2013; Mousavi et al. 2013), there is an emerging debate concerning the general functionality of eRNAs from several studies that suggest eRNAs are dispensable for enhancer function (Hah et al. 2013; Kaikkonen et al. 2013; Engreitz et al. 2016; Rahman et al. 2017). To examine the functional relevance of the inducible eRNAs that we have identified, we employed systematic siRNA- mediated eRNA knockdown (KD) assays and determined their target gene expression before and after siRNA transfection. In total, we used 85 siRNAs for depleting eRNAs of both induced and control EP pairs (Supplemental Tables S5-S7). Forty-nine siRNAs were able to reduce eRNA expression levels from 28 enhancers (eRNA fold change $[$ eFold] $<1$ ) (Supplemental Fig. S4; Supplemental Table S7). We performed statistical analysis and determined eFold $<0.7$ as a reasonable threshold for assessing the effectiveness of eRNA KD experiments (Fig. 4D). Eleven inducible and 12 control EP pairs that passed this threshold were further examined. All target genes in the inducible EP pairs were repressed by eRNA KD (Fig. 4E, left). In contrast, half of the target genes from the control EP pairs were not repressed, and some were even activated upon eRNA reduction (Fig. 4E, right). Representative cases from the inducible EP pairs are shown in Figure 4F. Similar to our 3C results, this knockdown analysis of eRNAs demonstrates that the inducible eRNAs are biochemically functional in mediating target gene activation.

\section{Inducible eRNAs promote physical interaction with target promoters}

According to our current $3 \mathrm{C}$ results and the results of previous reported studies (Banerjee et al. 2014; Schaukowitch et al. 2014), the transient physical association pattern was highly correlated with the transient transcription pattern of the target genes (Fig. 4A). Also, the eRNA KD results indicated functional relevance of these inducible eRNAs in the target gene transcription (Fig. 4E). Based on these results, we investigated if eRNAs play a general role in mediating physical interactions. We first analyzed the physical higher order chromatin interactions by $3 \mathrm{C}$ assay upon eRNA KD of the IFNB1 gene. This led to decreased physical interaction of the enhancer with the promoter by about 20\% (Supplemental Fig. S5A). We also examined the TNFSF10 locus containing three distinct inducible enhancers, enabling us to examine the effect of single eRNA KD on multiple EP interactions. Single eRNA KD led to dissociation of the corresponding enhancer from the promoter, as well as reduced interaction between the other enhancers and the TNFSF10 promoter (Interaction A-B in Fig. 5A,B) and among the three enhancers (Interaction $\mathrm{C}$ in Fig. 5A,B). The IFI35 and MYCBP2 EP pairs were analyzed as control pairs (Supplemental Fig. S5B,C). Their eRNA KD did not affect the interaction between the enhancer and the promoter. MYCBP2 eRNA KD resulted in an increase of EP interaction and the elevated target gene expression levels. This observation was not a unique case, as we have identified a number of eRNAs with similar functional profiles (Fig. 4E), suggesting there may be diverse classes of eRNAs (i.e., activatorand repressor-eRNAs). Results from these targeted studies suggest that inducible eRNAs exhibit a strong physical and functional association with the target genes. In contrast, noninducible eRNAs exhibit much weaker functional and physical association with the target genes.

\section{Multiple eRNAs collaborate in regulating target gene transcription}

Since genes can be regulated by a combination of multiple enhancers (Joo et al. 2016), we asked how might multiple inducible eRNAs coordinate their action on their target gene. We performed combinatorial eRNA KD by applying combined siRNAs to determine how eRNAs may function together. We examined the TNFSF10 gene, which has three inducible enhancers based on our analysis (\#5, \#30, and \#38, Fig. 5A). Single eRNA KD decreased EP interaction and TNFSF10 transcription (Fig. 5B,C). However, the effects on 
A validation of enhancer-promoter interaction

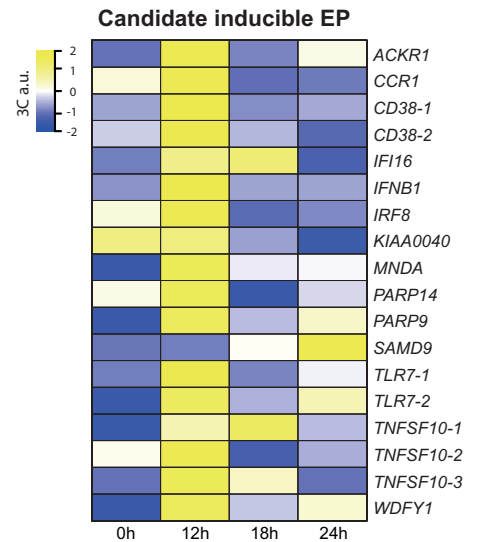

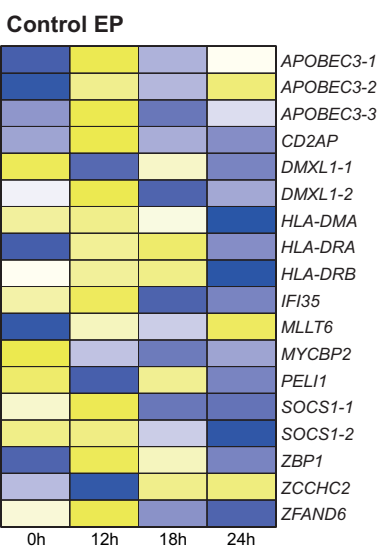

B physical interaction inducibility

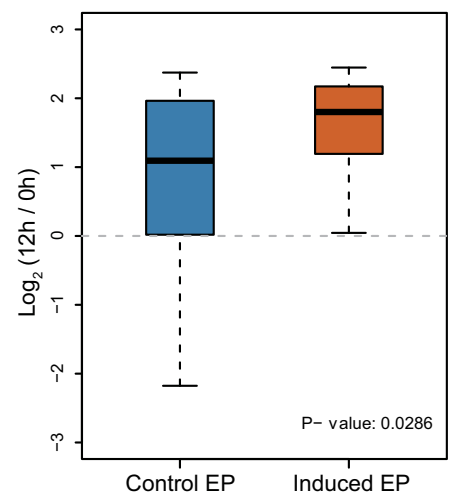

C correlation between interaction and transcription

IFNB1

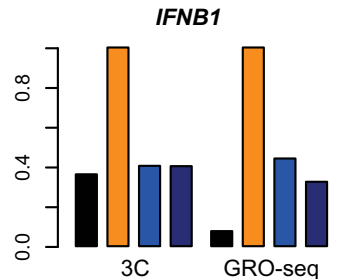

IRF8
TNFSF10

TLR7
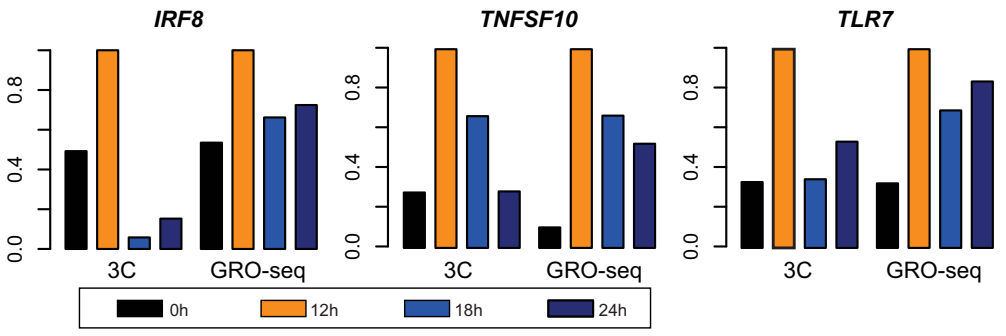

F representative examples of mRNA reduction by eRNA KD

D eRNA KD threshold based on mRNA level

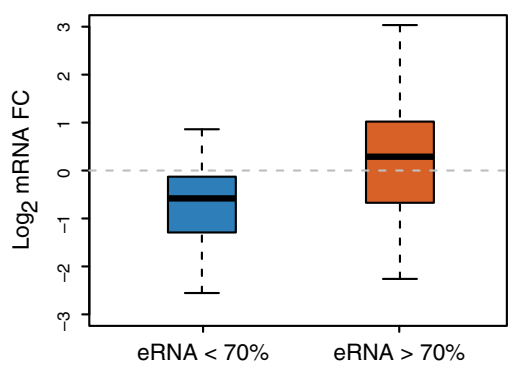

E eRNA and mRNA level in eRNA KD cells

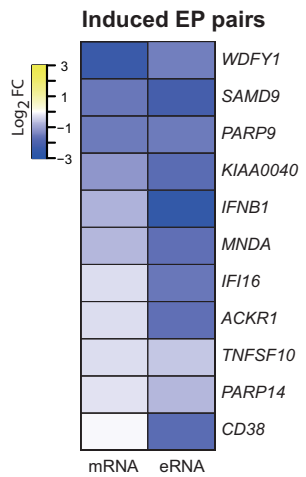

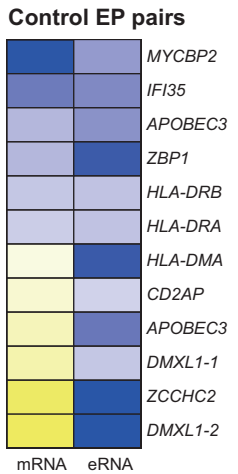
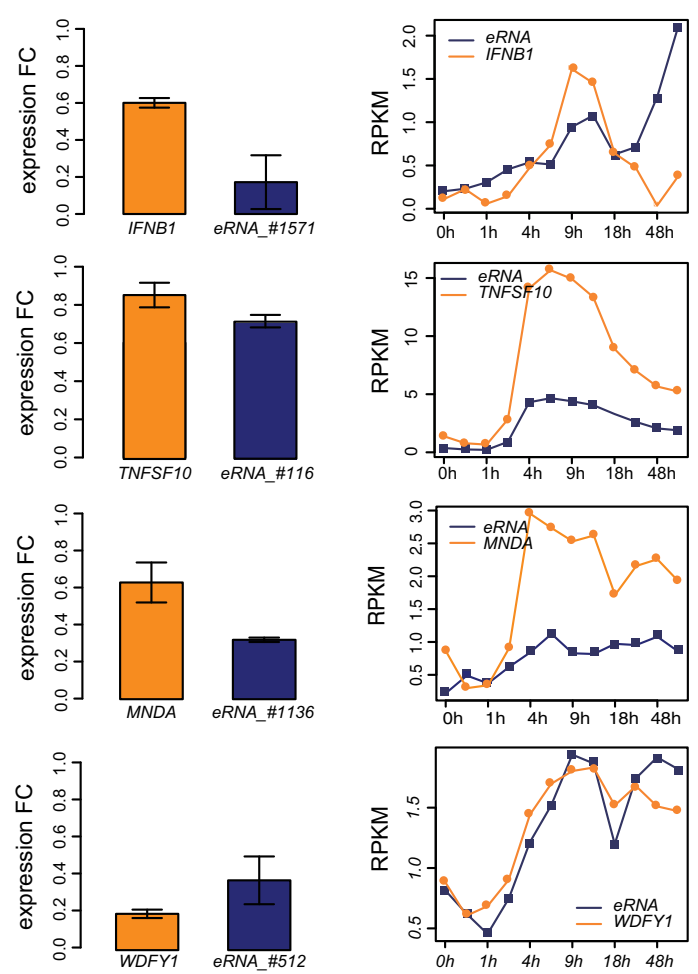

Figure 4. Effects of eRNA KD on target genes. (A) Heat maps of $3 C$ signals for 18 inducible EP pairs and 18 control EP pairs within $200 \mathrm{~kb}$ are shown. Signals are normalized by BAC $3 C$ interaction frequency. (B) Box plot of $3 C$ log fold changes is shown ( $12 \mathrm{~h}$ vs. $0 \mathrm{~h}$ ) for control and induced EP pairs with $P$-values from Kolmogorov-Smirnov (KS) test. (C) Representative examples of 3C results are shown and compared with GRO-seq signal (RPKM) of the corresponding immune-related genes. $(D)$ Box plot shows mRNA fold changes for successful eRNA KD (eRNA $<70 \%$ ) and unsuccessful eRNA KD (eRNA $>70 \%$ ). (E) Heat map shows mRNA/eRNA log fold changes; 11 inducible EP pairs and 12 control pairs are included. $(F)$ Representative examples of EP pairs where eRNA KD led to mRNA repression. mRNA/eRNA expression levels were measured by RT-qPCR. $y$-axes of expression curves represents GRO-seq signal (RPKM). 


\section{A EP interaction}

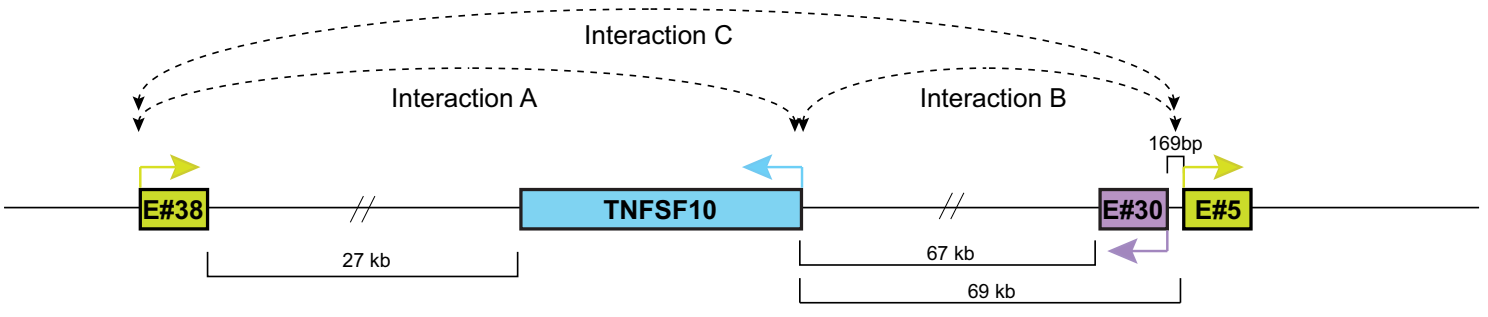

B interaction changes after TNFSF10 eRNA KDs
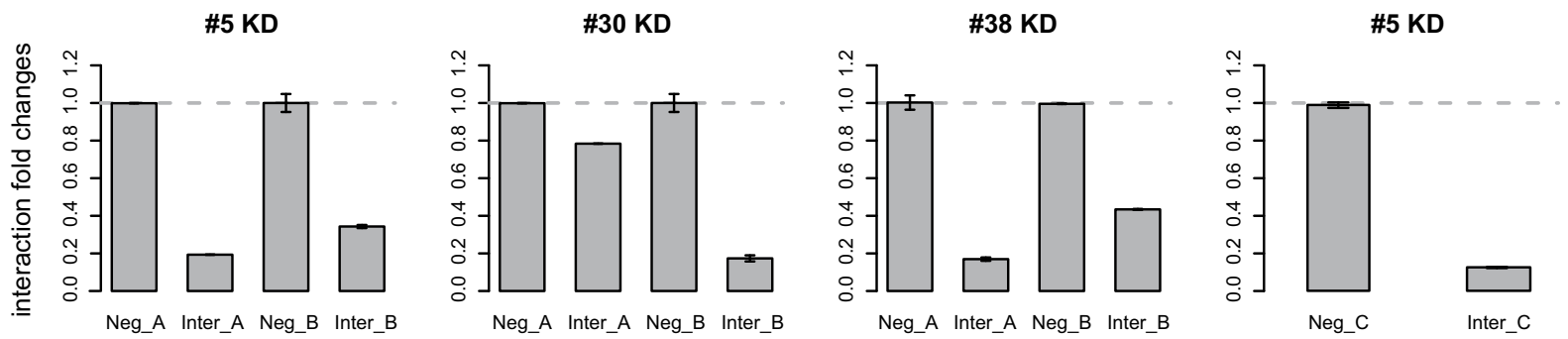

C expression changes after TNFSF10 eRNA KDs
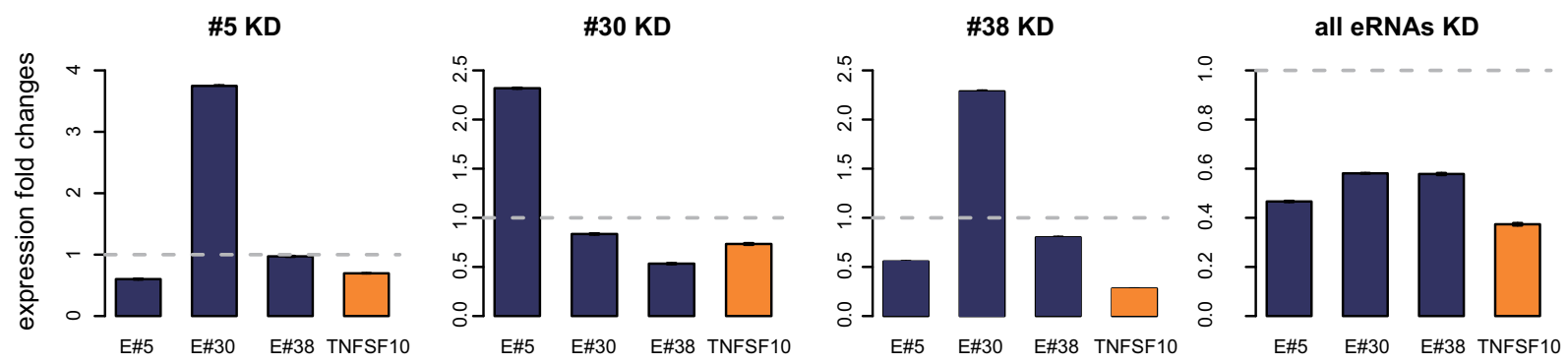

Figure 5. Effects of multiple enhancers on target gene expression and chromosomal conformation. (A) Schematic diagram of TNFSF10 gene with its multiple enhancers. TNFSF10 has \#38 enhancer $27 \mathrm{~kb}$ upstream, and \#30 and \#5 enhancers 67 and $69 \mathrm{~kb}$ downstream, respectively. Colored arrows from the gene and enhancer indicate transcriptional direction. Dashed lines show physical interaction between promoter and enhancer (Interaction A and B) or between different enhancers (Interaction C). (B) Interaction changes between enhancer and promoter regions (Interaction A and B) after individual eRNA KD and all three combined eRNA KD. (C) Three eRNAs (dark blue) and target gene (orange) expression fold changes after each individual eRNA $\mathrm{KD}$ and after all three eRNA KD by combining three corresponding siRNAs.

the levels of other eRNAs showed a complex pattern (Fig. 5C): \#5KD reduced \#38 but increased \#30; \#30KD decreased \#38 but increased \#5; \#38KD reduced \#5 but increased \#30. One clear pattern from this analysis is that there is a reciprocal and compensatory relationship between \#5 and \#30 eRNAs, which are bidirectional divergent transcripts originating from a single enhancer. This reciprocal effect was also observed in our previous work on the $L 2$ enhancer (Banerjee et al. 2014). When all three siRNAs were combined, all three eRNAs decreased, as well as the target TNFSF10 mRNA (Fig. 5C). We also analyzed the TLR7 and CD38 genes, each with two inducible eRNAs (Supplemental Fig. S6). Overlapping bidirectional eRNAs from TLR7 also showed the reciprocal effect under single eRNA KD. In the case of CD38, a distal eRNA (\#37) seems to be more dominant than a more proximal eRNA (\#17) in its contribution to the target gene activation. For both TLR7 and CD38, double $\mathrm{KD}$ of eRNAs reduced the corresponding mRNA expression incrementally. Taken together, these targeted analyses demonstrate how inducible eRNAs collaborate to support their target gene transcription. Overlapping, bidirectional eRNAs represent an interesting class of eRNAs displaying a compensating expression pattern upon knockdown and likely serve redundant roles to maintain the target gene expression. In addition, the transcriptional direction of eRNAs does not seem to be an important factor in determining their functional contribution to target gene expression.

\section{Targeting TNFSF10 eRNA activity limits apoptosis}

Thus far, our study has identified a validated set of functional eRNAs and established that modulation of these eRNAs can yield selective changes in target gene expression. These findings could be valuable for a therapeutic intervention by targeted enhancement or reduction of disease-relevant genes. In the context of the anti-viral response in human and mouse, overexpression of the TNFSF10 gene has been implicated in inducing lung damage by influenza virus (Hogner et al. 2013). We reasoned that, by targeted reduction of TNFSF10 eRNAs to decrease TNFSF1O expression, we may be able to limit apoptosis without affecting interferon production or response. In order to examine the possibility of eRNA modulation for reducing apoptosis, we performed siRNA-mediated reduction of TNFSF1O eRNAs and checked cell 
viability (Fig. 6A). TNFSF10 expression level, upon triple eRNA KD, decreased about 50\%, compared to the control (Fig. 6B). Control cells showed a stronger signal for cleaved caspase 3 than the TNFSF10 eRNA KD cells and a positive control, IFNB1 eRNA KD cells (Fig. 6C; Supplemental Fig. S8). Furthermore, reduction of TNFSF10 eRNA resulted in a higher proportion of live cells and a corresponding decrease in apoptotic cells (Fig. 6D). To confirm that TNFSF10 eRNA KD is specific for limiting the virusinduced apoptosis, we induced TNFSF1O expression by a distinct mechanism using TIC10, a small molecule inducer of FOXO3 that activates the TNFSF10 promoter (Jacob et al. 2014). Thus, TIC10 treatment would result in apoptosis via a distinct mechanism, compared to viral infection-induced apoptosis. As expected, TNFSF10 eRNAs KD, either individual KD or triple KD, did not af-

A simplified TNFSF10 regulatory network

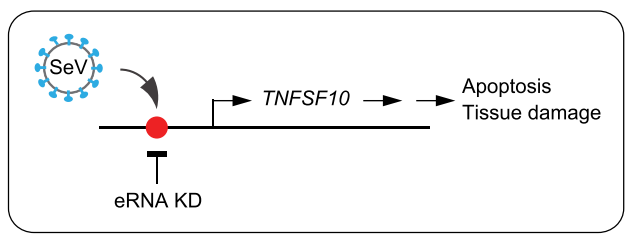

B eRNA KD reduces TNFSF10 expression

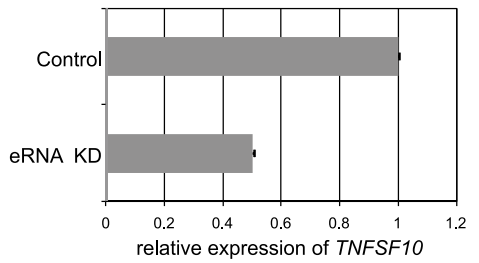

C eRNA KD reduces caspase 3 cleavage

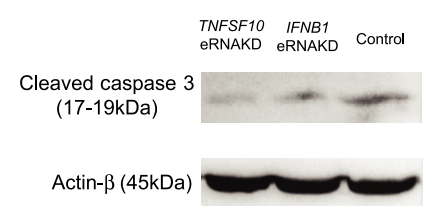

E TIC10-induced apoptosis
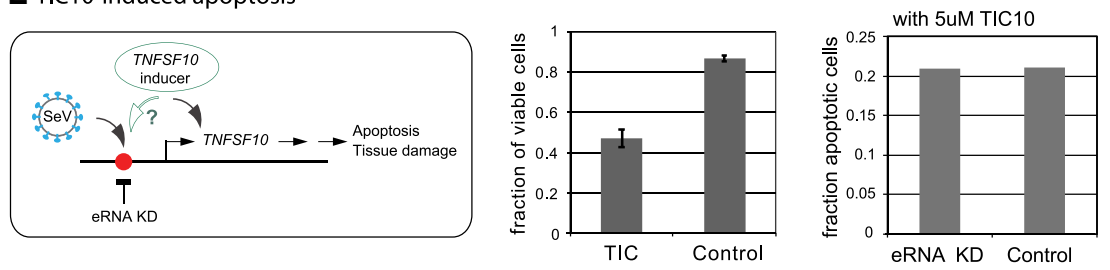

F Virus-inducible eRNAs do not respond to TIC10
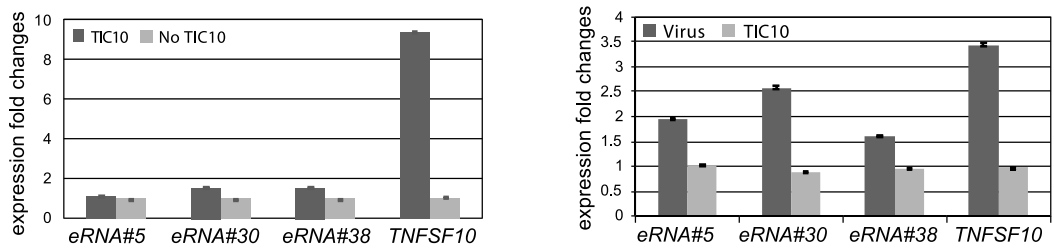

Figure 6. Effect of selective inhibition of TNFSF10 by eRNA knockdown on virus-induced apoptosis. (A) Simplified representation of the TNFSF10 regulatory network. (B) Relative expression of TNFSF10 in eRNA knockdowns (\#5, \#30, and \#38, triple eRNA KD) and control cells. Triple KD of eRNAs regulating the TNFSF10 results in loss of TNFSF10 expression. (C) Western blot using cleaved caspase 3 antibody to assess apoptosis. Stronger signal of cleaved caspase 3 indicates higher fraction of apoptotic cells. As an internal standard, beta actin was used. For an uncropped image of these blots, please see Supplemental Figure S8. (D) Cell viability by live cell counts (left panel) and apoptotic cell counts (right panel) for TNFSF10 eRNA KD and control cells are shown. (E) Regulation of apoptosis by TIC10- or virus-induced TNFSF10 expression. Possible mechanism through eRNA or direct gene activation is shown in the left panel. Cell viability by live cell counts (middle panel) for TIC10-treated cell, control cell, and apoptotic cell counts (right panel) for eRNA KD (triple KD) and control KD upon TIC10 treatment for $48 \mathrm{~h}$. $(F)$ TNFSF10 and its three eRNAs expression fold changes with or without TIC 10 treatment for $48 \mathrm{~h}$ (left panel), and with SeV or TIC10 treatment for $9 \mathrm{~h}$ (right panel). fect TIC10-induced apoptosis (Fig. 6E; Supplemental Fig. S7). In addition, TIC10 treatment induced TNFSF10 expression significantly, but it did not affect expression of the virus-inducible (Fig. 6F, left). In contrast, TNFSF10 gene (Fig. 6F, right). Taken together, these results demonstrate that targeted reduction of eRNAs can specifically inhibit interferon-induced apoptosis.

\section{Discussion}

Regulatory genomic elements outnumber genes by two orders of magnitude. More than two million enhancers have been annotated in the human genome (Romanoski et al. 2015). One fundamental question is whether all these enhancers are functionally equivalent or whether there are distinct classes of enhancers that are more relevant in different conditions. To explore the landscape of potentially functional enhancers and associated eRNAs, we used the virus-inducible gene expression model. We identified potentially functional eRNAs by taking advantage of the dynamic expression information from global transcriptional analysis and using associated genomic proximity and transcriptional activity as criteria. Specifically, we considered inducibility of enhancers upon virus infection and applied this activitybased association strategy to identify their target gene. From this strategy, we were able to assign 123 eRNAs to their most likely target genes. Using these highly confident EP pairs, we tested the functionality of eRNAs at both the physical interaction level and biochemical level. More than $80 \%$ of the inducible EP pairs showed a higher physical interaction frequency at $12 \mathrm{~h}$-a time point representing the peak of transcription level. In addition, reduction of eRNA levels by RNAi decreased target gene transcription for all inducible eRNAs tested. From these results, we conclude that the virusinducible eRNAs are indeed functional. The control pairs for our experiments were selected by general criteria that other groups have routinely used for determining active enhancers. Our $3 \mathrm{C}$ results and targeted eRNA reduction results from control sets might explain why many groups have argued that eRNAs are dispensable for enhancer function. Thus, co-inducibility of eRNAs and genes would be relevant for identifying other functional eRNAs in different biological conditions.

One unexpected finding from our study is that the fate of an enhancer can be different from the promoter it regulates after their transient functional and 
physical association. In many independent cases, eRNA production continues while the enhancer becomes disengaged from its associated promoter and the target gene undergoes post-induction repression. In other cases that conform to the current paradigm of gene regulation, when an enhancer disengages from its promoter, both eRNA and mRNA production are shut off concordantly. Furthermore, dependence of eRNAs for physical interaction between enhancers and promoters does not seem to be a universal mechanism across different loci (Li et al. 2013; Schaukowitch et al. 2014). Rather, each locus exhibits different dependencies on eRNAs for enhancer-promoter interaction. Notably, some loci display competition among enhancers and promoters when assayed for physical interaction. In reduced-function assays using RNAi, enhancers within the same locus can also compete for production of corresponding eRNAs. Despite the complex regulatory dependencies among enhancers and promoters, a combined reduction of all eRNAs for a given target gene resulted in the largest decrease in target gene expression compared to individual eRNA knockdowns, suggesting a complete pool of functionally relevant eRNAs is necessary for proper regulation. Thus, the human genome displays dynamic and complex exchanges of physical and functional associations among enhancers and promoters to define genome expression. These functional properties of eRNAs are consistent with a recently proposed model of RNA-mediated phase separation for gene regulation (Hnisz et al. 2017).

Lastly, we demonstrated that we can modulate one particular enhancer of the anti-viral program to achieve a specifically modified cellular behavior that can aid in reducing excessive inflammation. With hundreds of functional eRNAs identified in this study, targeted therapies with tailored modulation of multiple enhancers may be an approach to achieve a personalized clinical response.

\section{Methods}

\section{Cell culture and virus infection}

B-Lymphoblasts, GM12878, were obtained from Coriell Institute for Medical Research and cultivated according to the supplier's instructions. Fifteen percent fetal bovine serum was added to Roswell Park Memorial Institute media 1640 (RPMI-1640) with $2 \mathrm{mM}$ L-glutamine for the culture. Sendai Virus (Cantrell strain) obtained from Charles River was used for inducing anti-viral immune response- $50 \mu \mathrm{L}$ of viral stock was added to $1 \mathrm{~mL}$ media. Cell samples were taken at $30 \mathrm{~min}, 1,2,4,6,12,18,24,48$, and $72 \mathrm{~h}$ after virus infection for the GRO-seq experiment. For the other experiments, 3C assay and the ChIP-seq experiment, the cells incubated for $6,12,18$, and $24 \mathrm{~h}$ after infection were sampled. Untreated GM12878 cells were used as a control, which is the Oh sample.

\section{GRO-seq analysis}

Global run-on and library preparation for sequencing was performed based on the method published by John Lis et al. in 2008 (Core et al. 2008). To generate multi-indexing sequencing libraries, an Illumina TruSeq Small RNA Library Prep kit-set A (24 rxns, RS-200-0012) was used (Kim et al. 2013).

\section{Nuclei isolation}

Two 15-cm plates of confluent cells ( $\sim 10-20$ million cells) were washed three times with ice-cold PBS buffer and incubated for $5 \mathrm{~min}$ with $10 \mathrm{~mL}$ cold swelling buffer $(10 \mathrm{mM}$ Tris-Cl at $\mathrm{pH} 7.5$, $2 \mathrm{mM} \mathrm{MgCl}_{2}, 3 \mathrm{mM} \mathrm{CaCl}$ ) for each plate, on ice. Cells were scraped from the plate, harvested, centrifuged at $500 \mathrm{~g}$ for $10 \mathrm{~min}$ at $4^{\circ} \mathrm{C}$ and resuspended in $1 \mathrm{~mL}$ of lysis buffer (swelling buffer with $0.5 \%$ IGEPAL, $10 \%$ glycerol, and $4 \mathrm{U} / \mathrm{mL}$ SUPERaseIn) with gentle mixing by pipetting with a wide bore pipette tip up and down 20 times. For the isolation of nuclei, $9 \mathrm{~mL}$ of the same lysis buffer (up to total $10 \mathrm{~mL}$ ) was added. After collection by centrifugation (at $300 \mathrm{~g}$ for $5 \mathrm{~min}$ at $4^{\circ} \mathrm{C}$ ), the nuclei were resuspended in $1 \mathrm{~mL}$ freezing buffer per 5 million nuclei, pelleted, and resuspended to a final volume of $100 \mu \mathrm{L}$ (about 5-10 million nuclei/100 $\mu \mathrm{L}$ ) of freezing buffer $\left(50 \mathrm{mM}\right.$ Tris-Cl at $\mathrm{pH} 8.3,5 \mathrm{mM} \mathrm{MgCl}_{2}, 0.1 \mathrm{mM}$ EDTA, $40 \%$ glycerol).

\section{Nuclear Run-On (NRO)}

Before the NRO reaction, NRO reaction buffer $(10 \mathrm{mM}$ Tris-Cl at pH 8.0, $5 \mathrm{mM} \mathrm{MgCl}_{2}, 1 \mathrm{mM}$ DTT, $300 \mathrm{mM} \mathrm{KCl}, 50 \mu \mathrm{M}$ ATP, GTP and Br-UTP, $2 \mu \mathrm{M}$ CTP, $0.4 \mathrm{U} / \mu \mathrm{L}$ RNasin, and $2 \%$ sarkosyl) was prepared and preheated to $30^{\circ} \mathrm{C}$ for $5 \mathrm{~min}$. An equal volume $(100 \mu \mathrm{L})$ of NRO reaction buffer was mixed with $100 \mu \mathrm{L}$ of thawed nuclei solution in freezing buffer and was incubated at $30^{\circ} \mathrm{C}$ for $5 \mathrm{~min}$ with mixing at $800 \mathrm{rpm}$ on a thermomixer. Then, RQ1 DNaseI (Promega) was added along with DNaseI reaction buffer and samples were incubated at $37^{\circ} \mathrm{C}$ for $20 \mathrm{~min}$ with mixing at $800 \mathrm{rpm}$. To stop the NRO reaction, $225 \mu \mathrm{L}$ NRO stop solution was added to the reaction and $25 \mu \mathrm{L}$ of Proteinase K was added. The sample was incubated for $1 \mathrm{~h}$ at $55^{\circ} \mathrm{C}$. Nuclear RNA was extracted with acidic phenol (Sigma) and then with chloroform (Sigma) and was precipitated and washed. RNA was then resuspended in $20 \mu \mathrm{L}$ of nuclease-free water and subjected to base hydrolysis by addition of $5 \mu \mathrm{L}$ of $1 \mathrm{~N} \mathrm{NaOH}$ on ice for $10 \mathrm{~min}$. The reaction was neutralized with $50 \mu \mathrm{L}$ of $0.5 \mathrm{M}$ Tris- $\mathrm{Cl}$ at $\mathrm{pH}$ 6.8. Then, RNA was purified through a Bio-Rad P-30 RNase-free spin column following the manufacturer's instructions and was treated with $7 \mu \mathrm{L}$ of DNaseI buffer and $3 \mu \mathrm{L}$ RQ1 DNaseI (Promega) for $10 \mathrm{~min}$ at $37^{\circ} \mathrm{C}$ and purified again with a Bio-Rad P-30 column.

\section{Br-UTP binding}

Anti-BrdU (clone IIB5) agarose beads (Santa Cruz Biotech, sc$32323 \mathrm{AC}$ ) were equilibrated by washing them two times in 500 $\mu \mathrm{L}$ BrU binding buffer $(0.25 \times$ SSPE, $1 \mathrm{mM}$ EDTA, $0.05 \%$ Tween20, $37.5 \mathrm{mM} \mathrm{NaCl})$ and blocked in $1 \mathrm{~mL} \mathrm{BrU}$ blocking buffer $(1 \times$ binding buffer, $0.1 \%$ PVP, and $1 \mathrm{mg} / \mathrm{mL} \mathrm{BSA}$ ) for $1 \mathrm{~h}$ with rotation at $4^{\circ} \mathrm{C}$. During the blocking step, beads were washed two times with $500 \mu \mathrm{L}$ binding buffer, the NRO RNA sample was heated at $65^{\circ} \mathrm{C}$ for $5 \mathrm{~min}$ and then placed on ice for at least $2 \mathrm{~min}$. Fifty microliters of the blocked bead mixture were combined with RNA sample in $450 \mu \mathrm{L}$ binding buffer and mixed for $1 \mathrm{~h}$ by rotating at $4^{\circ} \mathrm{C}$. After binding, beads were washed once in low-salt buffer (0.2× SSPE, $1 \mathrm{mM} \mathrm{EDTA,} 0.05 \%$ Tween-20), once in high-salt buffer (0.25 $\times$ SSPE, $1 \mathrm{mM}$ EDTA, $0.05 \%$ Tween-20, $137.5 \mathrm{mM} \mathrm{NaCl})$, and twice in TET buffer (TE with $0.05 \%$ Tween-20). BrU-incorporated RNA was eluted four times with $100 \mu \mathrm{L}$ elution buffer $(20 \mathrm{mM}$ DTT, $300 \mathrm{mM} \mathrm{NaCl}, 5 \mathrm{mM}$ Tris-Cl at pH 7.5, $1 \mathrm{mM}$ EDTA, and $0.1 \%$ SDS). RNA was then extracted and precipitated as described above. The precipitated RNA was resuspended in $20 \mu \mathrm{L}$ of water.

\section{TAP/PNK treatment}

RNA was heated to $65^{\circ} \mathrm{C}$ for $5 \mathrm{~min}$ and cooled on ice for at least $2 \mathrm{~min}$. The RNA was treated with TAP (by adding $3 \mu \mathrm{L} 10 \times$ TAP buffer, $5 \mu \mathrm{L}$ water, $1 \mu \mathrm{L}$ SUPERaseIn [Promega], $0.5 \mu \mathrm{L}$ TAP) at $37^{\circ} \mathrm{C}$ for $1.5 \mathrm{~h}$, and then pre-incubated with PNK reaction premix (1 $\mu \mathrm{L}$ PNK [NEB], $1 \mu \mathrm{L} 300 \mathrm{mM} \mathrm{MgCl}, 1 \mu \mathrm{L} 100 \mathrm{mM}$ ATP) for 30 min. Afterward, PNK reaction main mix $(20 \mu \mathrm{L}$ PNK buffer [NEB], $2 \mu \mathrm{L} 100 \mathrm{mM}$ ATP [Roche], and $142 \mu \mathrm{L}$ water, $1 \mu \mathrm{L}$ SUPERaseIN [Promega], and another $2 \mu \mathrm{L}$ PNK [NEB]) was added 
to the pre-incubated RNA sample and incubated at $37^{\circ} \mathrm{C}$ for $30 \mathrm{~min}$. The RNA was extracted and precipitated again as above and resuspended in $9 \mu \mathrm{L} \mathrm{H}_{2} \mathrm{O}$.

\section{5 ' adapter ligation}

BrU-RNA, $5^{\prime}$ adapter $(5 \mu \mathrm{M})$, and PEG were heated at $65^{\circ} \mathrm{C}$ for $5 \mathrm{~min}$ then cooled on ice. Ligation mixture $\left(1.5 \mu \mathrm{L} 5^{\prime}\right.$ adapter $[5 \mu \mathrm{M}], 2 \mu \mathrm{L}$ $10 \times$ RNA ligation buffer, $1.5 \mu \mathrm{L}$ T4 RNA ligase, $1 \mu \mathrm{L}$ SUPERaseIn, $5 \mu \mathrm{L} 50 \%$ PEG 8000) was added to the $9 \mu \mathrm{L} \mathrm{BrU-RNA}$ and incubated at $22^{\circ} \mathrm{C}$ or RT for $4-6 \mathrm{~h}$. Then, $5^{\prime}$ adapter-ligated BrU-RNA was purified with the bead binding method as described above.

\section{3' adapter ligation}

The same ligation reaction for the $5^{\prime}$ adapter ligation described above was performed with the $3^{\prime}$ adapter in place of the $5^{\prime}$ adapter.

\section{$R T$ reaction}

RNA and RT oligo (5'-CAAGCAGAAGACGGCATACGA-3') were heated to $65^{\circ} \mathrm{C}$ for $10 \mathrm{~min}$ and cooled on ice. RT reagent mixture (1 $\mu \mathrm{L}$ RT oligo [100 $\mu \mathrm{M}$ ], $5 \times$ first strand buffer [Invitrogen], $10 \mathrm{mM}$ dNTPs [Roche], $100 \mathrm{mM}$ DTT [Invitrogen], $1 \mu \mathrm{L}$ RNase inhibitor [Promega] without Superscript III [Invitrogen]) was added to the RNA sample and incubated at $48^{\circ} \mathrm{C}$ for $3 \mathrm{~min}$, and then $1 \mu \mathrm{L}$ Superscript III was added to the RT reaction sample and incubated at $48^{\circ} \mathrm{C}$ for $20 \mathrm{~min}$ and $50^{\circ} \mathrm{C}$ for $45 \mathrm{~min}$, sequentially. After the RT reaction, RNA was eliminated by adding RNase cocktail and RNase $\mathrm{H}$ and incubating at $37^{\circ} \mathrm{C}$ for $30 \mathrm{~min}$.

\section{PCR amplification}

The ssDNA template was amplified by PCR using the Phusion High-Fidelity enzyme (NEB) according to the manufacturer's instructions. The small RNA PCR primers (5'-CAAGCAGAAGACGG CATACGA-3' and 5'-AATGATACGGCGACCACCGACAGGTT-3') were used to generate DNA for sequencing. PCR was performed with an initial 5 -min de-naturation at $98^{\circ} \mathrm{C}$, followed by $10 \sim 14 \mathrm{cy}-$ cles of 10 -sec denaturation at $98^{\circ} \mathrm{C}, 30$-sec annealing at $54^{\circ} \mathrm{C}$, and 15 -sec extension at $72^{\circ} \mathrm{C}$. The PCR product was purified by running on a $6 \%$ native polyacrylamide TBE gel and recovered by cutting the region of the gel between $100 \mathrm{bp}$ and $300 \mathrm{bp}$. The product was purified through the gel extraction method. The prepared DNA was then sequenced on the Illumina Genome Analyzer II according to the manufacturer's instructions with small RNA sequencing primer 5'-CGACAGGTTCAGAGTTCTACAGTCCGACG ATC-3'.

\section{eRNA annotation}

GRO-seq reads were mapped to human genome assembly hg18 using Bowtie 2 (Langmead and Salzberg 2012). We merged GRO-seq data across time points and used HOMER (Heinz et al. 2010) for de novo transcript identification with option "-style groseq". Intergenic transcripts, which were $>1 \mathrm{~kb}$ from $5^{\prime}$ ends and $>10 \mathrm{~kb}$ from $3^{\prime}$ ends of RefSeq gene annotations, were selected as eRNA candidates. The RefSeq annotation was downloaded through an R package called "GenomicFeatures" (Lawrence et al. 2013), with "GenomicFeature" version 1.20.3 and creation time "2015-11-24 13:48:33 -0600 (Tues., Nov. 24, 2015)". We filtered out regions that did not overlap with either H3K4me1 or H3K27ac peak regions.

ENCODE epigenetic data analyzed here can be downloaded from GEO under accession numbers GSE29611 (H3K4me1 and H3K27ac), GSE29692 (DNase-seq), GSE35586 (MNase-seq), and GSE31477 (EP300). Human enhancer atlas data were downloaded from http://slidebase.binf.ku.dk/human_enhancers/, the permissive enhancer set.

\section{Expression analysis of coding and noncoding transcription}

Expression levels of genes and enhancers were calculated as reads per kilobase per million (RPKM). R package DESeq2 (Love et al. 2014) was used to perform differential analysis between two time points. Differential gene sets were submitted to David Bioinformatics Resources Database (Huang da et al. 2009a,b) for functional enrichment analysis. Principle component analysis and t-distributed stochastic neighbor embedding methods were applied with expressed genes/enhancers (mean RPKM > 0.5) for data visualization.

We designed one-step delayed auto-correlation to control noise levels and the absolute fold change to identify responsive genes/enhancers. Selected genes/enhancers were subjected to clustering by the "Partitioning Around Medoids" (PAM) algorithm, resulting in three clusters: "inducible early," "inducible late," and "repressed."

\section{Determining inducible enhancers and genes}

We identified inducible enhancers/genes using the amplitude index and continuity index. The expression level at time $t$ is represented as $e(t)$. $A I$ is defined as the maximum logarithm fold increases before $24 \mathrm{~h}$,

$$
A I=\log _{2}\left[\frac{\max _{t \leq 24 \mathrm{~h}} e(t)}{e(0)}\right] .
$$

$\mathrm{CI}$ is defined as the one-step delayed auto-correlation, to filter out enhancers/genes with noisy expression pattern

$$
C I=\text { correlation }\left\{\left[e\left(t_{1}\right), \ldots, e\left(t_{n-1}\right)\right],\left[e\left(t_{2}\right), \ldots, e\left(t_{n}\right)\right]\right\} .
$$

We then selected enhancers and genes with $A I>1$ and $C I>0.2$ as inducible.

\section{Concordant and discordant EP pairs}

Inducible EP pairs were ranked by the Spearman's correlation coefficients (SCCs) between enhancers and genes. Pairs ranked at the top $30 \%$ and bottom $30 \%$ of the list are designated as concordant and discordant, respectively.

\section{Pairing enhancer and target genes}

Fold changes at each time point were calculated for enhancers near inducible genes. We divided enhancers into groups according to their distance from genes and found enhancers $<200 \mathrm{~kb}$ from these genes showed significantly stronger inducibility. We named inducible genes and enhancers within $200 \mathrm{~kb}$ distance as inducible EP pairs.

\section{Motif analysis}

We used TF binding motif PWM matrices from HOmo sapiens COmprehensive MOdel COllection (HOCOMOCO) v10 (Kulakovskiy et al. 2016). We applied HOMER module annotatePeaks.pl to identify motif occurrence in inducible enhancers and genes (see scripts in Supplemental_Script_S1).

\section{Synteny analysis}

We analyzed EP colocalization in 11 species covering different levels of metazoan animals, including chimp, marmoset, mouse, rat, guinea pig, rabbit, cow, dog, elephant, armadillo, and lizard. Orthologs of enhancers and promoters were identified using the

\section{Genome Research}

www.genome.org 
UCSC LiftOver tool with minimal match ratio set to 0.1 . We tested the percentage of inducible human EP pairs locating in the same chromosome in other species. For statistical analysis, we generated a background set by paring 10,000 random promoter regions with the same number of intergenic regions, following the distance distribution of inducible pairs.

\section{Chromatin immunoprecipitation (ChIP) sequencing}

Chromatin was prepared and immunoprecipitated as described previously (Kim et al. 2011), except that protein A/G Dynabeads (Invitrogen) were used instead of organism-specific secondary antibody bound beads. Twenty-five percent of the amount of chromatin was used to reduce oversaturation of bead binding capacity. H3K27ac antibody from Abcam (ab4729) was used for the ChIP experiment. The ThruPLEX DNA-seq kit from Rubicon Genomics was used for multiplexed ChIP-seq and input sample library prep of GM12878 chromatin. Indexed samples were quantitated with qPCR and mixed in equimolar amounts. The Yale Stem Cell Center Genomics and Bioinformatics Core Facility conducted the sequencing on an Illumina HiSeq 2000 platform. ChIP-seq peaks were called with MACS2 (Zhang et al. 2008) with the default mode. We analyzed our ChIP-seq data using deepTools2 (Ramirez et al. 2016) and customized scripts (see scripts in Supplemental_Script_S2).

\section{Chromosome conformation capture (3C)}

The 3C assay was performed as described (Kim et al. 2011; Banerjee et al. 2014), with minor modifications. Briefly, one million cells were crosslinked with $1 \%$ formaldehyde for $15 \mathrm{~min}$ at room temperature resuspended in lysis buffer $(10 \mathrm{mM}$ Tris- $\mathrm{Cl}$ at $\mathrm{pH} 8.0,10$ $\mathrm{mM} \mathrm{NaCl}$, and $0.2 \% \mathrm{NP}-40$ ), and incubated on ice for $90 \mathrm{~min}$. Ten million of these prepared nuclei were digested with EcoRI (New England Biolabs) overnight at $37^{\circ} \mathrm{C}$, followed by ligation with T4 DNA ligase (New England Biolabs) at $16^{\circ} \mathrm{C}$ for $4 \mathrm{~h}$. The ligated DNA was incubated with Proteinase $\mathrm{K}$ at $65^{\circ} \mathrm{C}$ for $12 \mathrm{~h}$ to reverse the crosslinks. Following incubation, the DNA was treated with RNase A. The treated DNA was extracted with phenol:chloroform and precipitated with sodium acetate and ethanol. The DNA concentration of the recovered 3C library was determined using a Qubit dsDNA HS assay kit (Invitrogen). Quantitative realtime PCR was performed to confirm the specific ligation between two DNA fragments in the sample and control 3C libraries. The position and sequence of primers designed for the 3C qPCR assay are listed in Supplemental Table S4. Interaction frequencies were calculated by dividing the amount of PCR product obtained with the sample 3C library constructed from nuclei by the amount of PCR product obtained with the control library DNA generated from ligating EcoRI fragments from the corresponding bacterial artificial clones (BAC) (Supplemental Table S4): interaction frequency $=2^{\left(\Delta C_{t} \text { sample- } \Delta C_{t} \text { control }\right)}$. All 3C analyses were performed, at a minimum, in triplicate.

\section{eRNA KD analysis with siRNA}

siRNA duplex for eRNA KD was obtained from Sigma-Aldrich. Their sequences and eRNA region of induced EP pairs and control EP pairs are listed in Supplemental Tables S5 and S6, respectively. As a negative control, scrambled siRNA was used. As a mock control, only transfection reagent without siRNA was added to the cell sample. Three hundred thousand cells were prepared in 800 $\mu \mathrm{L}$ media in each well of a 12-well plate. Separately, siRNA transfection solution was prepared by adding $1 \mu \mathrm{L}$ of siRNA $(10 \mu \mathrm{M}$ stock of siRNA) and $5 \mu \mathrm{L}$ of Mission siRNA transfection reagent (Sigma) to $200 \mu \mathrm{L}$ OPTI-MEM, followed by incubation for 15-20 min at room temperature. Then, siRNA transfection solution was added to the cells carefully, by dropping it, and incubated for $5 \mathrm{~h}$ at $37^{\circ} \mathrm{C}$, and then changed with fresh media. After $36 \mathrm{~h}$ of incubation, virus solution with the concentration of $50 \mu \mathrm{L} / \mathrm{mL}$ media was added to the cells to activate the inducible immune response gene system. After $12 \mathrm{~h}$, total RNA was extracted with adding $500 \mu \mathrm{L}$ of TRIzol solution (Invitrogen) to the cell pellet spun down at $1500 \mathrm{rpm}$ for $3 \mathrm{~min}$ and rotated at $4^{\circ} \mathrm{C}$ for $5 \mathrm{~min}$.

RT-qPCR was performed to check the transcription level after siRNA KD for eRNA and promoter RNA. Total RNA extract with TRIzol (Invitrogen) was treated with DNase I (Roche) for $30 \mathrm{~min}$ at $37^{\circ} \mathrm{C}$ and further extracted with acidic phenol:chloroform and precipitated with salt, glycogen, and pure ethanol. The RNA was reverse-transcribed using ImProm-II (Promega) with $100 \mu \mathrm{M}$ of oligo(dT) primers or random decamers. The resulting cDNA was incubated with $10 \mu \mathrm{g}$ of RNase $\mathrm{H}$ and RNase cocktail for $30 \mathrm{~min}$ at $37^{\circ}$ $\mathrm{C}$ and purified using a PCR purification kit (MACHEREY-NAGEL). Five to $10 \mathrm{ng}$ of purified cDNA was quantified by using a FastStart Universal SYBR Green Master Mix (Roche) on a qPCR machine (Realplex2, Eppendorf). We used GAPDH as the internal control. The GAPDH primers for RT-qPCR are: forward 5'-TGCACCA CCAACTGCTTAGC-3' and reverse 5'-GGCATGGACTGTGGTCAT GAG-3'. To calculate the relative expression fold change (sample/ control), we used the scrambled siRNA transfection as the negative control. The qPCR primers were designed against each siRNAtargeting region of eRNA and promoter, and the sequences of primers were listed in Supplemental Tables S8 and S9.

\section{Apoptosis assay}

To evaluate cell viability, we performed western blots with cleaved caspase 3 antibody (Cell Signaling Technology, \#9661) and an Annexin-V (ANXA5) apoptosis detection flow cytometry assay as described (Goodwin et al. 2017). Cells were infected at $36 \mathrm{~h}$ after siRNA transfection as described in the previous Methods section (targeting TNFSF10 eRNAs and IFNB1 eRNA, L2), and cells $(300,000$ per well) were harvested at 24,72 , and $96 \mathrm{~h}$ after virus infection with cold PBS wash. For the negative control experiment, 5 $\mu \mathrm{M}$ of TIC10 (SML1068, Sigma-Aldrich) were treated for $48 \mathrm{~h}$ to activate the apoptosis pathway by inducing the level of TNFSF10 expression.

For the western blot, in order to extract protein from each well, $40 \mu \mathrm{L}$ of RIPA buffer with freshly made proteinase inhibitor cocktail (Roche) was added to the cell pellet. A 12\% SDS gel was run for $1 \mathrm{~h}$ with constant voltage $(120 \mathrm{~V})$, followed by transfer to a membrane (Immun-Blot PVDF membrane sandwiches, Bio$\mathrm{Rad}$ ) with constant $0.1 \mathrm{~A}$ for $45 \mathrm{~min}$. The size of cleaved caspase 3 is $17-19 \mathrm{kDa}$. $\beta$-Actin (45 $\mathrm{kDa}$ ) was used as an internal standard.

For flow cytometry, cell death was measured using the PE Annexin-V Apoptosis Detection Kit I (BD Pharmingen) according to the manufacturer's instructions. Cells were collected and stained with annexin-V and 7-AAD and analyzed by flow cytometry (SH800, Sony) and FlowJo software.

\section{Data access}

GRO-seq and ChIP-seq data from this study have been submitted to the Array Express (http://www.ebi.ac.uk/arrayexpress/) under accession numbers E-MTAB-6047 and E-MTAB-6050.

\section{Acknowledgments}

We thank Yale Stem Cell Center for providing deep sequencing services. We thank Sean Megason for critical comments on the manuscript. We thank Michael Neugent for assistance with flow 
cytometry. We thank Sarah Sprinkle and Rashida Francis for editorial help and the members of the functional genomics laboratory at the University of Texas at Dallas for comments on the manuscript. M.Q.Z. and P.X. acknowledge support from the National Institutes of Health, grant R01 MH102616, Cecil H. and Ida Green Endowment Chair, and UTD Founder's Fellowship. T.H.K. has been supported by the Rita Allen Foundation, Sidney Kimmel Foundation for Cancer Research, Alexander and Margaret Stewart Trust, National Institute of Allergy and Infection Disease (R21AI107067), and National Cancer Institute (R01CA140485).

Author contributions: Y.J.K. designed, performed, and analyzed all experiments. P.X. analyzed the sequencing, 3C, and siRNA knockdown data. L.C. assisted in siRNA knockdown experiments. M.Q.Z. supervised data analysis. T.H.K. conceived and developed the genomic and functional validation experiments and provided overall direction and supervision of experiments and analyses. Y.J.K., P.X., and T.H.K. wrote the manuscript.

\section{References}

Andersson R, Gebhard C, Miguel-Escalada I, Hoof I, Bornholdt J, Boyd M, Chen Y, Zhao X, Schmidl C, Suzuki T, et al. 2014. An atlas of active enhancers across human cell types and tissues. Nature 507: 455-461. doi:10.1038/nature 12787

Arner E, Daub CO, Vitting-Seerup K, Andersson R, Lilje B, Drablos F, Lennartsson A, Ronnerblad M, Hrydziuszko O, Vitezic M, et al. 2015. Transcribed enhancers lead waves of coordinated transcription in transitioning mammalian cells. Science 347: 1010-1014. doi:10.1126/ science. 1259418

Banerjee AR, Kim YJ, Kim TH. 2014. A novel virus-inducible enhancer of the interferon- $\beta$ gene with tightly linked promoter and enhancer activities. Nucleic Acids Res 42: 12537-12554. doi:10.1093/nar/gku1018

Bradner JE, Hnisz D, Young RA. 2017. Transcriptional addiction in cancer. Cell 168: 629-643. doi: $10.1016 /$ j.cell.2016.12.013

Cao Q, Anyansi C, Hu X, Xu L, Xiong L, Tang W, Mok MTS, Cheng C, Fan X, Gerstein $\mathrm{M}$, et al. 2017. Reconstruction of enhancer-target networks in 935 samples of human primary cells, tissues and cell lines. Nat Genet 49: 1428-1436. doi:10.1038/ng.3950

Core LJ, Waterfall JJ, Lis JT. 2008. Nascent RNA sequencing reveals widespread pausing and divergent initiation at human promoters. Science 322: 1845-1848. doi:10.1126/science.1162228

Decque A, Joffre O, Magalhaes JG, Cossec JC, Blecher-Gonen R, Lapaquette P, Silvin A, Manel N, Joubert PE, Seeler JS, et al. 2016. Sumoylation coordinates the repression of inflammatory and anti-viral gene-expression programs during innate sensing. Nat Immunol 17: 140-149. doi: 10.1038/ni.3342

The ENCODE Project Consortium. 2007. Identification and analysis of functional elements in 1\% of the human genome by the ENCODE pilot project. Nature 447: 799-816. doi:10.1038/nature05874

Engreitz JM, Haines JE, Perez EM, Munson G, Chen J, Kane M, McDonel PE, Guttman M, Lander ES. 2016. Local regulation of gene expression by lncRNA promoters, transcription and splicing. Nature 539: 452-455. doi:10.1038/nature20149

Ernst J, Kellis M. 2010. Discovery and characterization of chromatin states for systematic annotation of the human genome. Nat Biotechnol 28: 817-825. doi: $10.1038 /$ nbt.1662

Goodwin J, Neugent ML, Lee SY, Choe JH, Choi $\mathrm{H}$, Jenkins DMR, Ruthenborg RJ, Robinson MW, Jeong JY, Wake M, et al. 2017. The distinct metabolic phenotype of lung squamous cell carcinoma defines selective vulnerability to glycolytic inhibition. Nat Commun 8: 15503. doi:10.1038/ncomms15503

Hah N, Murakami S, Nagari A, Danko CG, Kraus WL. 2013. Enhancer transcripts mark active estrogen receptor binding sites. Genome Res 23 1210-1223. doi:10.1101/gr.152306.112

Heintzman ND, Stuart RK, Hon G, Fu Y, Ching CW, Hawkins RD, Barrera LO, Van Calcar S, Qu C, Ching KA, et al. 2007. Distinct and predictive chromatin signatures of transcriptional promoters and enhancers in the human genome. Nat Genet 39: 311-318. doi:10.1038/ng1966

Heintzman ND, Hon GC, Hawkins RD, Kheradpour P, Stark A, Harp LF, Ye Z, Lee LK, Stuart RK, Ching CW, et al. 2009. Histone modifications at human enhancers reflect global cell-type-specific gene expression. Nature 459: 108-112. doi:10.1038/nature07829

Heinz S, Benner C, Spann N, Bertolino E, Lin YC, Laslo P, Cheng JX, Murre C, Singh H, Glass CK. 2010. Simple combinations of lineage-determining transcription factors prime cis-regulatory elements required for mac- rophage and B cell identities. Mol Cell 38: 576-589. doi:10.1016/j. molcel.2010.05.004

Heinz S, Romanoski CE, Benner C, Glass CK. 2015. The selection and function of cell type-specific enhancers. Nat Rev Mol Cell Biol 16: 144-154. doi:10.1038/nrm3949

Hnisz D, Shrinivas K, Young RA, Chakraborty AK, Sharp PA. 2017. A phase separation model for transcriptional control. Cell 169: 13-23. doi:10.1016/j.cell.2017.02.007

Hogner K, Wolff T, Pleschka S, Plog S, Gruber AD, Kalinke U, Walmrath HD, Bodner J, Gattenlohner S, Lewe-Schlosser P, et al. 2013. Macrophageexpressed IFN- $\beta$ contributes to apoptotic alveolar epithelial cell injury in severe influenza virus pneumonia. PLoS Pathog 9: e1003188. doi:10.1371/journal.ppat.1003188

Huang da W, Sherman BT, Lempicki RA. 2009a. Bioinformatics enrichment tools: paths toward the comprehensive functional analysis of large gene lists. Nucleic Acids Res 37: 1-13. doi:10.1093/nar/gkn923

Huang da W, Sherman BT, Lempicki RA. 2009b. Systematic and integrative analysis of large gene lists using DAVID bioinformatics resources. Nat Protoc 4: 44-57. doi:10.1038/nprot.2008.211

Jacob NT, Lockner JW, Kravchenko VV, Janda KD. 2014. Pharmacophore reassignment for induction of the immunosurveillance cytokine TRAIL. Angew Chem Int Ed 53: 6628-6631. doi:10.1002/anie.201402133

Jamieson AR, Giger ML, Drukker K, Li H, Yuan Y, Bhooshan N. 2010. Exploring nonlinear feature space dimension reduction and data representation in breast Cadx with Laplacian eigenmaps and $t$-SNE. Med Phys 37: 339-351. doi:10.1118/1.3267037

Jin F, Li Y, Dixon JR, Selvaraj S, Ye Z, Lee AY, Yen CA, Schmitt AD, Espinoza CA, Ren B. 2013. A high-resolution map of the three-dimensional chromatin interactome in human cells. Nature 503: 290-294. doi:10.1038/ nature 12644

Joo JY, Schaukowitch K, Farbiak L, Kilaru G, Kim TK. 2016. Stimulus-specific combinatorial functionality of neuronal c-fos enhancers. Nat Neurosci 19: 75-83. doi:10.1038/nn.4170

Kaikkonen MU, Spann NJ, Heinz S, Romanoski CE, Allison KA, Stender JD, Chun HB, Tough DF, Prinjha RK, Benner C, et al. 2013. Remodeling of the enhancer landscape during macrophage activation is coupled to enhancer transcription. Mol Cell 51: 310-325. doi:10.1016/j. molcel.2013.07.010

Kim TK, Hemberg M, Gray JM, Costa AM, Bear DM, Wu J, Harmin DA, Laptewicz M, Barbara-Haley K, Kuersten S, et al. 2010. Widespread transcription at neuronal activity-regulated enhancers. Nature 465: 182-187. doi:10.1038/nature09033

Kim YJ, Cecchini KR, Kim TH. 2011. Conserved, developmentally regulated mechanism couples chromosomal looping and heterochromatin barrier activity at the homeobox gene A locus. Proc Natl Acad Sci 108: 7391-7396. doi:10.1073/pnas.1018279108

Kim YJ, Greer CB, Cecchini KR, Harris LN, Tuck DP, Kim TH. 2013. HDAC inhibitors induce transcriptional repression of high copy number genes in breast cancer through elongation blockade. Oncogene 32: 2828-2835. doi:10.1038/onc.2013.32

Kulakovskiy IV, Vorontsov IE, Yevshin IS, Soboleva AV, Kasianov AS, Ashoor H, Ba-Alawi W, Bajic VB, Medvedeva YA, Kolpakov FA, et al. 2016. HOCOMOCO: expansion and enhancement of the collection of transcription factor binding sites models. Nucleic Acids Res 44: D116-D125. doi:10.1093/nar/gkv1249

Lai WKM, Pugh BF. 2017. Understanding nucleosome dynamics and their links to gene expression and DNA replication. Nat Rev Mol Cell Biol 18: 548-562. doi:10.1038/nrm.2017.47

Langmead B, Salzberg SL. 2012. Fast gapped-read alignment with Bowtie 2 Nat Methods 9: 357-359. doi:10.1038/nmeth.1923

Lawrence M, Huber W, Pages H, Aboyoun P, Carlson M, Gentleman R, Morgan MT, Carey VJ. 2013. Software for computing and annotating genomic ranges. PLoS Comput Biol 9: e1003118. doi:10.1371/journal pcbi.1003118

Li W, Notani D, Ma Q, Tanasa B, Nunez E, Chen AY, Merkurjev D, Zhang J, Ohgi K, Song X, et al. 2013. Functional roles of enhancer RNAs for oestrogen-dependent transcriptional activation. Nature 498: 516-520. doi: $10.1038 /$ nature 12210

Li W, Notani D, Rosenfeld MG. 2016. Enhancers as non-coding RNA transcription units: recent insights and future perspectives. Nat Rev Genet 17: 207-223. doi:10.1038/nrg.2016.4

Love MI, Huber W, Anders S. 2014. Moderated estimation of fold change and dispersion for RNA-seq data with DESeq2. Genome Biol 15: 550. doi:10.1186/s13059-014-0550-8

Melo CA, Drost J, Wijchers PJ, van de Werken H, de Wit E, Oude Vrielink JA, Elkon R, Melo SA, Leveille N, Kalluri R, et al. 2013. eRNAs are required for p53-dependent enhancer activity and gene transcription. Mol Cell 49: 524-535. doi:10.1016/j.molcel.2012.11.021

Mousavi K, Zare H, Dell'Orso S, Grontved L, Gutierrez-Cruz G, Derfoul A Hager GL, Sartorelli V. 2013. eRNAs promote transcription by 
establishing chromatin accessibility at defined genomic loci. Mol Cell 51: 606-617. doi:10.1016/j.molcel.2013.07.022

Rada-Iglesias A, Bajpai R, Swigut T, Brugmann SA, Flynn RA, Wysocka J. 2011. A unique chromatin signature uncovers early developmental enhancers in humans. Nature 470: 279-283. doi:10.1038/nature09692

Rahman S, Zorca CE, Traboulsi T, Noutahi E, Krause MR, Mader S, Zenklusen D. 2017. Single-cell profiling reveals that eRNA accumulation at enhancer-promoter loops is not required to sustain transcription. Nucleic Acids Res 45: 3017-3030. doi:10.1093/nar/gkw1220

Ramirez F, Ryan DP, Gruning B, Bhardwaj V, Kilpert F, Richter AS, Heyne S, Dundar F, Manke T. 2016. deepTools2: a next generation web server for deep-sequencing data analysis. Nucleic Acids Res 44: W160-W165. doi:10.1093/nar/gkw257

Ren B, Chee KJ, Kim TH, Maniatis T. 1999. PRDI-BF1/Blimp-1 repression is mediated by corepressors of the Groucho family of proteins. Genes Dev 13: 125-137. doi:10.1101/gad.13.1.125

Roadmap Epigenomics Consortium, Kundaje A, Meuleman W, Ernst J, Bilenky M, Yen A, Heravi-Moussavi A, Kheradpour P, Zhang Z, Wang $\mathrm{J}$, et al. 2015. Integrative analysis of 111 reference human epigenomes. Nature 518: 317-330. doi:10.1038/nature14248

Romanoski CE, Link VM, Heinz S, Glass CK. 2015. Exploiting genomics and natural genetic variation to decode macrophage enhancers. Trends Immunol 36: 507-518. doi:10.1016/j.it.2015.07.006
Sanyal A, Lajoie BR, Jain G, Dekker J. 2012. The long-range interaction landscape of gene promoters. Nature 489: 109-113. doi:10.1038/ nature 11279

Schaukowitch K, Joo JY, Liu X, Watts JK, Martinez C, Kim TK. 2014. Enhancer RNA facilitates NELF release from immediate early genes. Mol Cell 56: 29-42. doi:10.1016/j.molcel.2014.08.023

Thurman RE, Rynes E, Humbert R, Vierstra J, Maurano MT, Haugen E, Sheffield NC, Stergachis AB, Wang H, Vernot B, et al. 2012. The accessible chromatin landscape of the human genome. Nature 489: 75-82. doi:10.1038/nature11232

Wang D, Garcia-Bassets I, Benner C, Li W, Su X, Zhou Y, Qiu J, Liu W, Kaikkonen MU, Ohgi KA, et al. 2011. Reprogramming transcription by distinct classes of enhancers functionally defined by eRNA. Nature 474: $390-394$. doi: $10.1038 /$ nature10006

Whalen S, Truty RM, Pollard KS. 2016. Enhancer-promoter interactions are encoded by complex genomic signatures on looping chromatin. Nat Genet 48: 488-496. doi:10.1038/ng.3539

Zhang Y, Liu T, Meyer CA, Eeckhoute J, Johnson DS, Bernstein BE, Nusbaum C, Myers RM, Brown M, Li W, et al. 2008. Model-based Analysis of ChIP-Seq (MACS). Genome Biol 9: R137. doi:10.1186/gb-2008-9-9-r137

Received December 8, 2017; accepted in revised form October 10, 2018. 


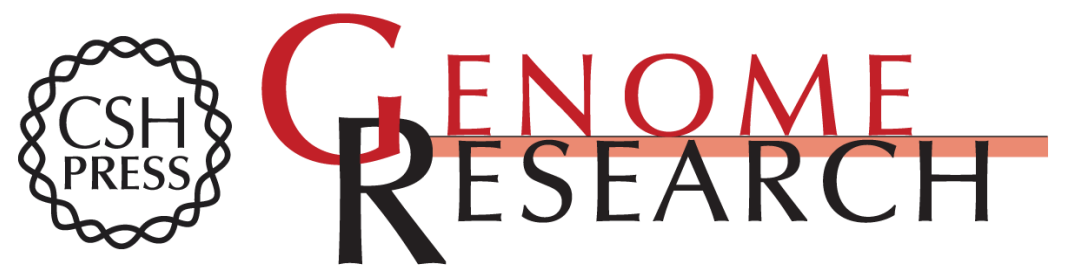

\section{Global transcriptional activity dynamics reveal functional enhancer RNAs}

Yoon Jung Kim, Peng Xie, Lian Cao, et al.

Genome Res. 2018 28: 1799-1811 originally published online October 23, 2018

Access the most recent version at doi:10.1101/gr.233486.117

Supplemental Material

References

Open Access

Creative Commons

License

Email Alerting Service
http://genome.cshlp.org/content/suppl/2018/11/02/gr.233486.117.DC1

This article cites 49 articles, 4 of which can be accessed free at: http://genome.cshlp.org/content/28/12/1799.full.html\#ref-list-1

Freely available online through the Genome Research Open Access option.

This article, published in Genome Research, is available under a Creative Commons License (Attribution 4.0 International), as described at http://creativecommons.org/licenses/by/4.0/.

Receive free email alerts when new articles cite this article - sign up in the box at the top right corner of the article or click here.

\section{Affordable, Accurate Sequencing.}

